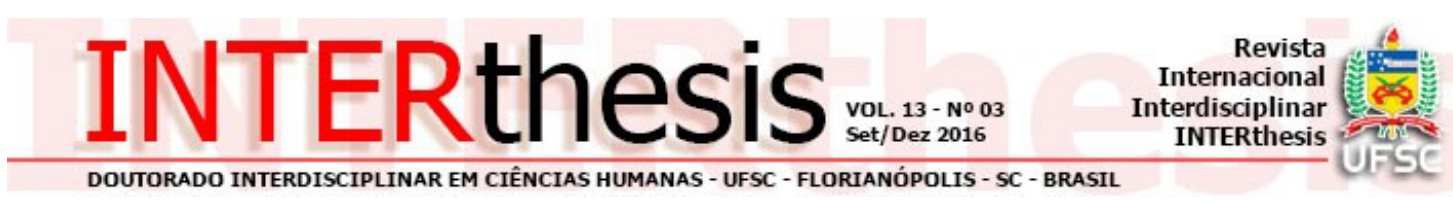

\title{
LUTA ANTICORRUPÇÃO COMO EXERCÍCIO DE CIDADANIA ATIVA
}

\section{Resumo:}

Teresa Cristina Coelho Matos ${ }^{1}$ Maria D'Alva Macedo Ferreira²

Este artigo aborda sobre as iniciativas engendradas na dimensão da sociedade civil para a fiscalização das contas públicas, pelo exercício de cidadania ativa, na perspectiva da luta anticorrupção. Decorre de pesquisa de doutorado em Políticas Públicas, delimitada no Estado do Piauí, trazendo como discussão teórica a ampliação do conceito de controle social para o controle democrático no contexto da sociedade brasileira. A investigação empírica foi realizada por meio de observação direta, à luz da observação participante, junto à experiência vivenciada pela Força Tarefa Popular (FTP), um movimento de articulação da sociedade que, desde 2002, realiza um trabalho de sensibilização e mobilização de pessoas e entidades para a prática cidadã de fiscalizar, diretamente, os investimentos públicos, visando prevenir e combater a corrupção.

Palavras-chave: Cidadania Ativa. Controle Democrático. Combate à Corrupção.

\section{INTRODUÇÃO}

A corrupção tem figurado como uma das principais preocupações da atualidade, por causar danos ao conjunto da sociedade, na dimensão econômica, política e social, sendo mais danosa no campo da gestão pública por atingir, sobretudo, os mais pobres, o que lhe torna um dos fatores de aumento das injustiças e das desigualdades sociais, comprometendo a qualidade da democracia. Diante disso, entidades e pessoas têm se mobilizado, no mundo todo, em busca de alternativas para sua prevenção e combate, tanto nos espaços institucionalizados do Estado quanto no contexto da sociedade civil.

Dando centralidade às alternativas engendradas na sociedade civil, compreende-se que a prática da cidadania ativa é um importante mecanismo de luta anticorrupção, sendo este o principal enfoque do presente artigo. A discussão está situada no contexto brasileiro, ilustrada pela experiência vivenciada, no Estado do

\footnotetext{
${ }_{1}$ Doutora em Políticas Públicas pela Universidade Federal do Piauí, Teresina, PI, Brasil. Assistente Social, Especialista em Gestão de Organizações Públicas e Sociais pela Universidade Estadual do Piauí, Teresina, PI, Brasil E-mail: teresacristina88@gmail.com

2 Doutora em Serviço Social pela Pontifícia Universidade Católica de São Paulo, São Paulo, SP, Brasil. Professora na Universidade Federal do Piauí, Teresina, PI, Brasil E.mail: mdalvaferreira@uol.com.br
} 
Piauí, pela Força Tarefa Popular (FTP), um movimento de articulação da sociedade civil que se constitui como um espaço aberto para a prática política do controle democrático e de luta anticorrupção no campo da gestão pública, como meio alternativo e viável para combater e prevenir a corrupção e seus efeitos.

$\mathrm{O}$ trabalho está estruturado em três seções. Inicia por uma projeção da ideia de controle social institucionalizado (do Estado sobre a sociedade) para a de controle democrático (da sociedade sobre o Estado). Em seguida, com base em debates acadêmicos, traz reflexões acerca da temática da corrupção, que tem incomodado e chamado atenção de diversos setores da sociedade e ganha tamanha dimensão por incidir na deslegitimação da representatividade do Estado e no desrespeito aos direitos de cidadania. Por último, expõe a experiência de cidadania ativa como mecanismo para fiscalizar as ações estatais e combater a corrupção, tecendo considerações sobre os entraves e possibilidades que se apresentam para o alcance desse propósito.

\section{DO CONTROLE SOCIAL INSTITUCIONALIZADO AO CONTROLE DEMOCRÁTICO}

Como assinala Correia (2005), a ideia de controle social está presente desde a formação do Estado moderno e vem mudando conforme as transformações socioeconômicas e políticas ocorridas no mundo, associada às mais diversas formas assumidas pelo Estado, ao longo da história. Nesse contexto está presente a corrupção, considerada, em geral, como um fenômeno inerente a todas as formas de governo e que se materializa por práticas ilícitas em busca de vantagens pessoais em prejuízo dos interesses da sociedade (KLITGAARD, 1994).

Sob a égide do Estado patrimonial, caracterizado pela não distinção entre bens públicos e privados, comum entre os séculos XVI e XVIII, a prática do controle social se dá pelo governante para com os súditos, sendo a corrupção um de seus principais atributos. É que, ao se operar a lógica de não se respeitar a separação entre interesses públicos e privados, cria-se uma situação de obtenção de privilégios pelo governante, em desfavor da população, cuja ação política, como afirma Weber (1982), é exercida pela relação de subordinação do povo ao patriarca e se legitima

R. Inter. Interdisc. INTERthesis, Florianópolis, v.13, n.3, p.23-42 Set.-Dez. 2016 
pela dominação de tipo tradicional do "ontem eterno". Ou seja, por força do costume e do conformismo.

Com o estabelecimento do capitalismo, no século XIX, e sua evolução para a produção industrial, no século XX, o modelo patrimonialista de Estado perde sua pujança ao se adotar o modelo burocrático, caracterizado pelo controle racional, hierárquico e formalista na gestão pública, o que, pela tese weberiana, evitaria o nepotismo e a corrupção presentes no modelo patrimonialista. Com isso, no contexto da sociedade capitalista industrial o controle social é transferido do domínio do soberano para o da burocracia, porém a corrupção permanece no seio do Estado, com efeitos danosos para a sociedade, na forma de conexões e acordos espúrios entre os segmentos burocráticos, políticos e econômicos.

O controle social passa a ser concebido na perspectiva da sociedade civil com o fortalecimento de grupos sociais, decorrente de avanços nos processo democrático, possibilitando uma nova relação com o Estado. Esses processos provêm das lutas políticas em defesa da propriedade social e igual distribuição das riquezas, que caracteriza a ideologia socialista, em contraposição ao predomínio da ideologia capitalista, que defende a produção social e a propriedade privada. Essa tendência de avanço do socialismo sobre o capitalismo levou os países capitalistas centrais a adotarem uma mentalidade defensiva de sua hegemonia, com destaque para a formação do Estado de Bem-Estar Social, estruturado e expandido no período pós-guerra, conforme ressalta Arretche (1995), com o papel de conciliar democracia e capitalismo, assegurando pleno emprego e políticas sociais universalistas.

No início da década de 1970 o capitalismo enfrenta uma das suas grandes crises, caracterizada pelos altos níveis de desemprego, hiperinflação e desaceleração das economias. Os países capitalistas avançados atribuem tal crise ao processo de globalização, produzido e expandido, em grande medida, pela revolução tecnológica e do conhecimento, como também ao excesso de burocracia e de políticas universalistas do Estado de Bem-Estar (THUROW, 1997). Para enfrentar essa crise, como mostra Pereira (1999), nos anos de 1980 os países capitalistas lideram um movimento global de modernização do Estado, que se consolida na década de 1990, voltado para descentralizar as ações estatais, privatizar as atividades econômicas e substituir o modelo de gestão burocrático pelo de gestão

R. Inter. Interdisc. INTERthesis, Florianópolis, v.13, n.3, p.23-42 Set.-Dez. 2016 
gerencial, com o argumento de tornar o aparato estatal mais ágil e mais compatível com as exigências do mundo globalizado.

O modelo de gestão gerencial funda-se na concepção neoliberal, que defende a restrição do Estado interventor em grau mínimo na economia, com o propósito de encontrar soluções para os problemas de oferta de serviços públicos, aí incluindo a transferência do controle social do âmbito do formalismo burocrático para o da sociedade civil. Esse modelo atende ao receituário do Consenso de Washington ${ }^{3}$, de reestruturação do Estado que prevê a fiscalização dos gastos públicos pela sociedade com a criação de espaços de participação na gestão de políticas públicas (NOGUEIRA, 2004). Contudo, conforme Simionatto (2010), a participação proposta, vinculada ao ideário neoliberal, visa atender mais às liberdades individuais e às regras do mercado do que resolver os graves problemas sociais presentes no contexto da sociedade globalizada, aos quais se somam as mazelas da corrupção que a burocracia, por si só, não foi capaz de controlar.

No Brasil, com histórico de luta pela consolidação da democracia e pela conquista de cidadania, um desafio que se põe na atualidade é que a prática do controle social, sob a ótica gerencialista, que concebe a participação da sociedade civil como instrumento de legitimação do Estado neoliberal, seja substituída pela prática do controle democrático, compreendido como a capacidade de participação direta de sujeitos sociais, individuais e coletivos, na fiscalização e no controle das ações estatais, influenciando nas decisões políticas, na qualidade da gestão pública e no combate à corrupção.

Destaca-se que a ampliação do controle social institucionalizado para o democrático requer mudanças qualitativas na relação entre Estado e Sociedade, na perspectiva dada por Gramsci (2000), de Estado ampliado, pela qual a sociedade civil atua não em contraposição a este, mas como sua dimensão ética. O pensador compreende essas instâncias como unidades orgânicas incumbidas de estabelecerem uma relação justa entre si, concebendo sociedade civil como um espaço privilegiado de correlação de forças entre classe sociais e com instâncias

\footnotetext{
${ }^{3}$ Evento, realizado em 1989, onde os sete países mais ricos (Estados Unidos, Alemanha, Canadá, Japão, Inglaterra, França e Itália), os grandes bancos internacionais (BID e BIRD) e o Fundo Monetário Internacional (FMI), discutiram e definiram estratégias para o enfrentamento da crise econômica mundial, dentre elas a implantação de um novo modelo de Estado (PEREIRA, 1999).
}

R. Inter. Interdisc. INTERthesis, Florianópolis, v.13, n.3, p.23-42 Set.-Dez. 2016 
estatais, atuando como base material na busca de direção política e consensos. Isso possibilita aumentar-lhe a capacidade de intervenção na gestão pública, direcionando-a para a criação e a garantia de direitos de cidadania.

\section{LUTA ANTICORRUPÇÃO COMO EXERCÍCIO DE CIDADANIA: REFLEXÕES TEÓRICAS}

A corrupção se manifesta de diversas formas e vai desde pequenas fraudes até altas transações ilícitas, tanto no setor público, quanto no setor privado, mas, como destaca Klitgaard (1994), é no aparato do Estado que ela produz os efeitos mais lesivos para a coletividade, como: 1) perda de eficiência na oferta de bens e serviços, pelo desperdício e má distribuição dos recursos; 2) perda na distribuição equitativa, por beneficiar ricos e privilegiados; 3) vícios na política de incentivos, na medida em que o pagamento gratificações estimule agentes públicos a extorquirem dinheiro dos cidadãos, sem thes prestar um bom serviço ou mesmo serviço algum; 4) instabilidade política, quando o comportamento corrupto torna-se habitual, levando o governo a descrédito público ou à alienação do povo.

No campo conceitual, predomina a ideia de que a corrupção é inerente a todas as sociedades e formas de governo, constituindo-se num ato de desrespeito para com a ética e uma ameaça à qualidade da democracia, além de gerar alto custo econômico em desfavor das classes subalternizadas, beneficiando ricos e poderosos (KLITGAARD, 1994; STUKART, 2003; AVRITZER, 2008; FILGUEIRAS, 2008).

Situadas no contexto da sociedade capitalista atual e analisadas à luz do pensamento marxista, as transações corruptas contribuem para reforça a estrutura de domínio de uma classe por outra, provocando efeitos lesivos na esfera econômica, por comprometer e dificultar o desenvolvimento; na esfera política, por afetar a qualidade da democracia e deslegitimar o sistema político e na esfera social, por aumentar desigualdades e injustiças. Como preceitua Marx (1999), analisando a luta de classes na França, a elite burguesa faz da política um negócio, se apossa do poder estatal e o explora pelos meios e pelos fins mais corruptos, e seus órgãos, que deveriam ser servidores da sociedade, são convertidos em seus opressores.

R. Inter. Interdisc. INTERthesis, Florianópolis, v.13, n.3, p.23-42 Set.-Dez. 2016 
Esta é uma característica que marca o capitalismo, uma vez que, no seu processo de desenvolvimento, vai se modernizando pela via dos sistemas burocráticos, no entanto, utilizados para responder aos requisitos formais e contábeis que mascaram a aplicação dos fundos públicos aplicados para atender aos interesses dos grupos econômicos e políticos de poder.

Em uma perspectiva culturalista, estas práticas contraditórias, próprias do modo de produção capitalista, aparecem como fazendo parte de comportamentos dos indivíduos, o que contribui para simplificar as formas de enfrentamento criadas no campo institucional, fundamentadas no Estado Democrático de Direito. Como destaca Klitgaard (1994), na sociedade contemporânea as ações de profilaxia e assepsia da corrupção são dificultadas, sobretudo, ao se justificar sua prática pelo viés cultural. Para preveni-la, o autor propõe que se evite o fatalismo cultural e se adotem medidas que tornem essa prática arriscada demais para que se incorra nela, propondo a máxima ampliação do acesso à informação, pois, conforme esclarece, "a corrupção é menos predominante quando há ampla informação sobre o que os agentes estão fazendo (KLITGAARD, 1994, p.220)".

Para seguir o caminho apresentado por Klitgaard (1994), aponta-se como alternativa viável o exercício da cidadania, assimilada não apenas pela concepção tradicional de conquista de direitos civis, políticos e sociais (MARSHAL, 1967), mas também na perspectiva ampliada conforme Chauí (1984) apresenta, de luta política para a criação de direitos e de espaços democráticos de participação direta, consistindo no que chama de cidadania ativa, que é aquela

\begin{abstract}
[...] capaz de fazer o salto do interesse ao direito, [...] de colocar no social a existência de um sujeito novo, de um sujeito que se caracteriza pela sua autoposição como sujeito de direitos, que cria esses direitos e no movimento da criação desses direitos exige que eles sejam declarados, cuja declaração abra o reconhecimento recíproco. O espaço da cidadania ativa, portanto é o da criação dos direitos, da garantia desses direitos e da intervenção, da participação direta no espaço da decisão política. A cidadania ativa é aquela que opera para interferir no interior do Estado (CHAUÍ, 1984, p. 47).
\end{abstract}

A corrupção no Brasil manifesta-se, no campo da gestão pública, por desvios e mau uso dos recursos por agentes públicos, representantes políticos e de setores econômicos, numa prática recorrente e de alto custo. Como ilustração disso, dados apresentados por especialista durante $\circ 5^{\circ}$ Encontro Global da Comunidade de Práticas Anticorrupção, realizado em 2012, pelo Programa das Nações Unidas para

R. Inter. Interdisc. INTERthesis, Florianópolis, v.13, n.3, p.23-42 Set.-Dez. 2016 
o Desenvolvimento (PNUD), mostraram que o prejuízo causado ao país pela corrupção atinge a cifra de bilhões de reais ao ano, o que se confirma, por exemplo, com a investigação de corrupção iniciada em março de 2014 na Empresa Brasileira de Petróleo (PETROBRAS), a maior empresa multinacional do Estado brasileiro. A investigação, conhecida como "Operação Lava Jato", estima o desvio de aproximadamente 10 bilhões de reais, por agentes públicos e privados, conforme dados preliminares colhidos pela Polícia Federal.

Outro exemplo que se acrescenta é o ranking do Brasil no Mapa da Corrupção no Mundo divulgado, anualmente, pela Transparência Internacional (TI) ${ }^{4}$. Em 2015, num rol de 168 países, o Brasil ocupa a 76 posição no Índice de Percepção da Corrupção (IPC) no setor público. Observa-se, conforme o quadro 1, que a incidência da corrupção ainda é muito grande no país e que a variação de colocação nesse ranqueamento, na última década, tem sido mínima.

Quadro 1 - Percepção da corrupção do Brasil no contexto mundial

\begin{tabular}{|l|l|l|l|l|l|l|l|l|l|l|}
\hline & 2006 & 2007 & 2008 & 2009 & 2010 & 2011 & 2012 & 2013 & 2014 & 2015 \\
\hline Nota & 33 & 35 & 35 & 37 & 37 & 38 & 43 & 42 & 43 & 38 \\
\hline $\begin{array}{l}\text { Ranking } \\
\text { mundial/ } \\
\text { Brasil }\end{array}$ & $70^{\circ}$ & $72^{\circ}$ & $80^{\circ}$ & $75^{\circ}$ & $69^{\circ}$ & $73^{\circ}$ & $69^{\circ}$ & 72 & $69^{\circ}$ & 76 \\
\hline $\begin{array}{l}\text { N }^{\circ} \text { de } \\
\text { países }\end{array}$ & 163 & 180 & 180 & 180 & 178 & 183 & 176 & 177 & 175 & 168 \\
\hline
\end{tabular}

Fonte: Construção própria com base nos dados da TI < http://www.transparency.org/cpi2015 >

A recorrência da corrupção no Brasil e sua posição elevada no cenário mundial são atribuídas, em parte, a uma tendência de naturalização das condutas corruptas na administração pública, assim como no cotidiano das pessoas, associada, sobretudo, a uma cultura política de matriz patrimonialista, formada desde a colonização do país. Essa vertente de pensamento, como observa Filgueiras (2008), explica a corrupção e a desonestidade como um traço do caráter da população brasileira, herdado do Estado patrimonial, ao invés de analisá-la pela vertente da construção social, de dimensão sistêmica, com reflexos no plano

\footnotetext{
${ }^{4}$ A Transparência Internacional (TI), fundada em 1993, é uma organização que atua no controle da corrupção em nível internacional e criou o Índice de Percepção da Corrupção (IPC), que apresenta, anualmente, o ranking da corrupção no mundo (http://www.transparency.org ).
}

R. Inter. Interdisc. INTERthesis, Florianópolis, v.13, n.3, p.23-42 Set.-Dez. 2016 
político, econômico, social e cultural, o que possibilitará melhor the dimensionar a abrangência e implicações na sociedade.

Filgueiras (2011) acrescenta que a pujança da corrupção na gestão pública brasileira tem relação com a política de transparência implementada sob a tutela da burocracia estatal, sem a utilização de mecanismos fortes de participação da população. Desse modo, gera, principalmente, uma política de escândalos que produz baixo impacto no controle e na punição dos agentes corruptos e maior exposição das patologias institucionais, resultando numa baixa confiança na eficácia do sistema de integridade brasileiro e uma sensação de impunidade.

Pela análise de Pinto (2011), existe uma rede de corrupção no Brasil que funciona dentro e fora do aparato estatal e the confere o status de "forma de governar". Para a autora, o caráter dado à corrupção como componente da cultura brasileira, desde o período colonial, é empecilho para sua análise e compreensão numa conjuntura de modernidade e de construção democrática. Chama atenção para os modos de inclusão e exclusão no contexto da modernidade brasileira, muitas delas legitimadas constitucionalmente, produzindo as "hierarquias das desigualdades", na qual se encontram as condições e possibilidades das práticas corruptas.

Herança cultural, monopólio burocrático da transparência e hierarquia das desigualdades são categorias de análise usadas para os que argumentam que há pouco engajamento da população brasileira na luta anticorrupção, mas, numa perspectiva dialética (NETO, 2011), essas mesmas categorias de análise podem ser consideradas como estímulo para que o problema da corrupção tenha aparecido como pauta, desde junho de 2013 , nos protestos de rua protagonizados por milhares de brasileiros, inicialmente contra o aumento das tarifas de transportes urbanos e que se estenderam para outras questões incômodas à sociedade brasileira.

Considera-se que a ida das pessoas às ruas, como vem ocorrendo no Brasil recente, tem grande significado sociopolítico, pois indica que o processo de democratização brasileiro avançou e, por outro lado, conforme Nogueira (2013), evidencia que a crise de representatividade e legitimidade das instituições cresceu e que é grande a insatisfação da população com a oferta dos serviços públicos, vindo a desencadear um movimento de contestação e de prática de cidadania ativa que alcança ressonância nos poderes executivo, legislativo e judiciário.

R. Inter. Interdisc. INTERthesis, Florianópolis, v.13, n.3, p.23-42 Set.-Dez. 2016 
Essas instâncias de poder estatal, com a legitimidade abalada e exposta à crítica pública, se viram impelidas a dar respostas às demandas da sociedade para 0 combate à corrupção, destacando-se: a) aprovação do projeto de lei que torna a corrupção crime hediondo ( $P L n^{\circ} 5.900 / 2013$ ); b) derrubada e arquivamento da Proposta de Emenda à Constituição (PEC no 37/2011), que retiraria o poder de investigação do Ministério Público; c) promulgação da Emenda Constitucional $n^{\circ}$ $76 / 2013$, que acaba com o voto secreto em processos de cassação de mandato parlamentar; d) aprovação da PEC no 284/2013, proibindo a nomeação, na administração pública, de condenados em ação judicial por crime de corrupção; d) aprovação da Lei Anticorrupção Empresarial (n 12.846/2013), que responsabiliza as pessoas jurídicas, civil e administrativamente, pela prática de atos ilícitos contra a administração pública, (SENADO FEDERAL; CÂMARA FEDERAL, 2014).

Ainda que algumas dessas medidas não tenham avançado da formalização para a efetividade na prevenção e combate às práticas corruptas na gestão pública brasileira, servem para confirmar a assertiva de Marilena Chauí de que o exercício da cidadania ativa interfere no interior do Estado e contribui para a obtenção de ganhos qualitativos na relação entre Estado e sociedade e abre espaço para se avançar do campo do controle social institucionalizado dos investimentos públicos para o controle democrático pela participação direta da sociedade civil no enfretamento e no combate à corrupção.

\section{PRÁTICA DE CIDADANIA ATIVA NO CONTROLE DO ESTADO E NA LUTA ANTICORRUPÇÃO: VIVÊNCIA NO PIAUÍ - BRASIL}

A participação direta na gestão pública requer como base a existência de um projeto de transformação da sociedade pela democracia, no sentido atribuído por Coutinho (2008, p.151), para quem a democracia "é soberania popular, é construção de uma comunidade participativa, é igualdade". Consiste numa democracia de massa que amplia a participação da sociedade para além do exercício de votar, característico dos regimes democráticos liberais. Refere-se, desse modo, a um movimento circular (haverá participação se houver democracia e haverá democracia se houver participação), que contribui para o aprofundamento do processo democrático e exige a constituição de espaços públicos compreendidos, à luz do

R. Inter. Interdisc. INTERthesis, Florianópolis, v.13, n.3, p.23-42 Set.-Dez. 2016 
pensamento de Arendt (1997), como lugar singular de participação política de sujeitos coletivos nas decisões de interesse público.

Essa possibilidade de prática cidadã se apresenta para a sociedade brasileira com a queda da ditadura militar, na segunda metade da década de 1980, e com a promulgação da Constituição de 1988, na qual se estabelecem condições favoráveis ao processo de democratização do país, incluindo a participação social, como direito, na gestão e no controle social das ações do Estado. Esse ambiente tem proporcionado uma ação política nova, que inclui a adoção de mecanismos de transparência e de accountability, no âmbito do aparato estatal.

O uso desses dois mecanismos, como assinala Pereyra (2013), forma o novo consenso anticorrupção entre os estudiosos da atualidade. Przeworski (2010), Barowiak (2011), Avritzer e Filgueiras (2011) apontam a transparência e a accountability como indispensáveis para o enfrentamento da corrupção no contexto das democracias representativas contemporâneas e como formas de diminuir o poder discricionário do agente público e promover-lhe a responsabilização democrática, contribuindo para ampliar o controle da sociedade sobre o Estado.

Nessa direção, de acordo com Barowiak (2011), o conceito de transparência corresponde às respostas que $\mathrm{o}$ agente público se obriga a dar pelas ações realizadas e às sanções sofridas conforme suas respostas e desempenhos. A compreensão de accountability é a de responsabilização democrática para, além da punibilidade, criar parceria entre governos e sociedade civil e contribuir para a formação da opinião pública e de novas formas de solidariedade.

No Brasil atual, o aparato do Estado com o papel de promover transparência e accountability no serviço público é formado, principalmente, pelo Ministério Público Federal (MPF), responsável pela defesa do regime democrático e dos direitos sociais e individuais (arts. 127 e 128 da Constituição), pelo Tribunal de Contas da União (TCU), auxiliar do Poder Legislativo no controle externo das contas públicas (arts. 71 a 74 e 161 da Constituição) e pela Controladoria Geral da União (CGU) ${ }^{5}$ criada para defender o patrimônio público e garantir a transparência no Poder Executivo (Lei $n^{\circ}$ 10.683/2003). Cabe a essas instâncias fazer funcionar um "Sistema Nacional de Integridade", compreendido como estrutura holística e

${ }^{5}$ A CGU foi extinta em maio de 2016, pelo governo interino de Michel Temer, e substituída pelo Ministério da Transparência, Fiscalização e Controle, criado pela Medida Provisória 726/2016, com as mesmas competências e atribuições daquela.

R. Inter. Interdisc. INTERthesis, Florianópolis, v.13, n.3, p.23-42 Set.-Dez. 2016 
cooperativa entre tais instituições e os atores sociais, empenhado em estabelecer um aparato forte de reforma anticorrupção (SPECK, 2002, p. 12).

Ressalta-se que participação política e prática de cidadania são ações que possibilitam o enfrentamento da corrupção na dimensão da sociedade civil. Nessa perspectiva, vem sendo gestada no Brasil uma rede social de luta anticorrupção, formada por organizações e atores que, mesmo ainda pouco abrangente, abre caminho para a construção de um círculo virtuoso alinhado à assertiva de RoseAckerman (2002) de que o controle da corrupção requer uma estrutura e organização interna do aparato estatal sobre o qual ocorra pressão da sociedade.

Ancorada na ideia de cidadania ativa, essa rede anticorrupção atua na vigilância da conduta dos agentes públicos e na aplicação dos recursos para a execução de obras e oferta de serviços pelo Estado, principalmente em contextos locais (estaduais e municipais). É formada por grupos não institucionalizados de fiscalização, independentes, no dizer de Rose-Ackerman (2002), cuja atuação tem alcançado maior visibilidade e conseguido mobilizar e sensibilizar sujeitos individuais e coletivos para a luta anticorrupção em dimensão nacional, como os seguintes:

1) Movimento de Combate a Corrupção Eleitoral (MCCE), criado em 1996, com sede em Brasília, formado por 50 entidades de vários segmentos da sociedade. Destacou-se na coordenação da campanha de mobilização social para a aprovação da Lei Complementar n 135/2010, a "Lei da Ficha Limpa".

2) Associação de Amigos de Ribeirão Bonito (AMARRIBO), fundada em 1999, nesse município de São Paulo, para combater a corrupção em nível local, mas ganhou expressão nacional ao formar uma rede anticorrupção com 210 entidades, passando a se denominar AMARRIBO BRASIL e, em 2014, é escolhida como representante da Transparência Internacional no Brasil.

3) Força Tarefa Popular (FTP), fundada em 1999, no Estado do Piauí, como um movimento de articulação de organizações e entidades para o controle social e o combate à corrupção pelo uso de mecanismos de democracia direta, tendo como principal estratégia a "Marcha Contra a Corrupção e Pela Vida".

4) Instituto de Fiscalização e Controle (IFC), com sede em Brasília, criado em 2005, por profissionais da área de fiscalização e controle do poder público, tem por objetivo, conforme o Estatuto Social, "incentivar e fortalecer as ações

R. Inter. Interdisc. INTERthesis, Florianópolis, v.13, n.3, p.23-42 Set.-Dez. 2016 
de acompanhamento e fiscalização da gestão financeira dos recursos públicos", tanto pela sociedade civil quanto pelos órgãos públicos.

5) Articulação Brasileira de Combate à Corrupção e Impunidade (ABRACCI), fundada em 2009, com a finalidade de congregar o conjunto de organizações e movimentos sociais engajados na luta contra a corrupção.

O Estado do Piauí está representado nessa rede pela Força Tarefa Popular (FTP), um movimento de articulação que se forma, a partir de 1999, como espaço aberto para a prática da cidadania ativa, numa conjuntura de desbaratamento do crime organizado no Estado e de denúncias de corrupção no âmbito dos governos estadual e municipais. Constitui-se por cidadãos e organizações representativas de diferentes segmentos sociais, urbanos e rurais, que se juntam pelo propósito compartilhado do exercício do controle democrático dos investimentos públicos, especialmente nos municípios piauienses com grande dificuldade de acesso à informação e maior vulnerabilidade à corrupção na gestão pública.

A principal estratégia de luta anticorrupção da FTP, desde 2002, é a "Marcha Contra a Corrupção e Pela Vida". Um símbolo de luta dos movimentos sociais que a FTP utiliza como força mística no sentido dado por Boff (1993, p.35), como "o conjunto de convicções profundas [...] que mobilizam as pessoas e [os] movimentos na vontade de mudanças [...]". Por meio da Marcha vivencia o desafio do exercício da cidadania ativa reinventando caminhos para a formação de uma cultura cívica, na perspectiva de Arendt (1997), estimulando a participação da sociedade em espaços públicos para deliberar e influenciar decisões no sistema político.

No ano de 2015, no período de 16 a 24 de junho, aconteceu a $14^{\text {a }}$ Marcha Contra a Corrupção e Pela Vida. Somadas às outras edições, ao longo de um trajeto de $3.086 \mathrm{~km}$, já reuniu mais de mil marchantes e passou por 91 municípios, fiscalizando convênios e obras levados a debate popular, cujo resultado tem sido, dentre outros, a conclusão de pavimentação de ruas, construção de escolas, perfuração de poços tubulares em comunidades rurais, além da formalização de denúncias aos órgãos de controle contra gestores municipais que aplicaram mal ou não prestaram contas dos recursos públicos.

R. Inter. Interdisc. INTERthesis, Florianópolis, v.13, n.3, p.23-42 Set.-Dez. 2016 
Quadro 2 - Demonstrativo das marchas realizadas pela FTP (2002-2015)

\begin{tabular}{|l|l|l|}
\hline Ano / Marcha & Percurso realizado & Km \\
\hline 2002 / I - Marcha & Picos a Teresina & $308 \mathrm{~km}$ \\
\hline 2003 / II Marcha & Parnaíba a Teresina & $332 \mathrm{~km}$ \\
\hline 2004 / III Marcha & Floriano a Teresina & $234 \mathrm{~km}$ \\
\hline 2005 / IV Marcha & Posses (GO) a Brasília (DF) & $252 \mathrm{~km}$ \\
\hline 2006 / V Marcha & Luzilândia a Teresina & $280 \mathrm{~km}$ \\
\hline 2007 / VI Marcha & Teresina a Santa Cruz dos Milagres & $194 \mathrm{~km}$ \\
\hline 2008 / VII Marcha & Buriti dos Montes a Teresina & $246 \mathrm{~km}$ \\
\hline 2009 / VIII Marcha & São João do PI a Floriano & $326 \mathrm{~km}$ \\
\hline 2010 / IX Marcha & Acauã a Picos & $151 \mathrm{~km}$ \\
\hline 2011 / X Marcha & Pio IX a Picos & $154 \mathrm{~km}$ \\
\hline 2012 / XI Marcha & Marcolândia a Picos & $123 \mathrm{~km}$ \\
\hline 2013 / XII Marcha & Guaribas a São Raimundo Nonato & $254 \mathrm{~km}$ \\
\hline 2014 / XIII Marcha & Queimada Nova a São João do Piauí & $153 \mathrm{~km}$ \\
\hline $2015 /$ XIV Marcha & Goiania (GO) a Brasília (DF) & $200 \mathrm{Km}$ \\
\hline
\end{tabular}

Fonte: Força Tarefa Popular

Mobilização e capacitação são as dimensões de maior expressão e as que melhor caracterizam a FTP, evidenciadas intensa e intencionalmente na realização da Marcha Contra a Corrupção, com a utilização de instrumentos de sensibilização e estímulos para que a população se engaje na fiscalização dos recursos públicos e na luta anticorrupção, quais sejam:

a) articulação institucional - construção de parcerias com instituições governamentais e da sociedade civil para obter envolvimento político e apoio financeiro e material para a realização da Marcha, além de construir alianças e trocas sinérgicas para a formação de uma cultura de intolerância à corrupção;

b) aula da cidadania - espaço público construído em cada município por onde a Marcha passa para compartilhar conhecimentos e informações sobre a temática do controle social e da transparência pública, através de palestras, apresentação de slides, vídeos, exposição fotográfica, matérias jornalísticas e relatos de casos exitosos de enfrentamento da corrupção;

R. Inter. Interdisc. INTERthesis, Florianópolis, v.13, n.3, p.23-42 Set.-Dez. 2016 
c) ocupação cívica - um ato, não violento, de ocupação da Câmara de Vereadores, para o exercício direto de fiscalização das contas públicas, numa ação de capacitação em processo da população local, sendo realizada com respaldo na Constituição Federal, para estimular o acesso do povo às Câmaras;

d) fiscalização de obras e convênios - ato de vistoria da aplicação dos recursos públicos no local da obra ou entidade executora, tendo à mão o plano de trabalho e o cronograma de repasse dos recursos, para conferir se a obra ou os serviços estão sendo realizados e pagos conforme os termos legalmente acordados;

e) organização de núcleos fiscalizatórios - ação de estimular a formação de um grupo, composto por atores locais, para animar a população a uma prática contínua do exercício do controle democrático, fiscalizando as contas públicas e realizando o acompanhamento das sessões na Câmara Municipal.

A Marcha não é um evento isolado, segue um movimento que mobiliza entidades e pessoas no mundo para promover a transparência pública e o combate à corrupção utilizando-se, dentre outras ferramentas, da internet, na qual a Força Tarefa interage pelo site www.focatarefapopular.org, em página no Facebook (Força Tarefa), e pelo blog forcatarefapopular.blogspot.com.br, expondo para a população as atividades que realiza, através da divulgação de vídeos, projetos e campanhas de sensibilização, além de estabelecer trocas interativas de informações com outras entidades, compondo o ambiente de um novo formato de mobilização de atores coletivos para o exercício da cidadania ativa.

\section{CONSIDERAÇÕES FINAIS}

Com base nas reflexões teóricas e nas experiências empíricas que ilustram a luta anticorrupção, pelo exercício da cidadania ativa, as premissas e inferências que se anunciam são apresentadas a seguir.

Mesmo a prática de corrupção sendo considerada uma preocupação mundial, pelo alto custo social que gera, e figurar em patamar muito elevado no Brasil, as vitórias alcançadas, apesar de importantes, não têm se mostrado suficientes para a obtenção de resultados que suplante o vigor da corrupção, fomentando a reflexão sobre alternativas e condições concretas para a sua prevenção e combate por meio de esforços compartilhados entre a sociedade e o aparato estatal.

R. Inter. Interdisc. INTERthesis, Florianópolis, v.13, n.3, p.23-42 Set.-Dez. 2016 
Na esfera do Estado, o Brasil conta com um Sistema Nacional de Integridade que, apesar de ter criado mecanismos de transparência e accountability, necessita avançar na utilização de formatos mais efetivos de participação da sociedade e na punibilidade aos agentes corruptos e corruptores, impondo-lhes medidas punitivas mais rigorosas e em proporção que ultrapassem os benefícios obtidos, para resultar em desestímulo à prática de ilícitos. Na dimensão da sociedade civil, tem sido de grande importância a atuação da rede social de luta anticorrupção em formação no país, mesmo que ainda em pouca medida diante da abrangência e dos danos causados pela corrupção, mas indica que a sociedade civil, no Brasil, vem se colocando em movimento para participar diretamente da gestão pública.

O estudo de caso, no contexto do Estado do Piauí, mostra que o controle das ações estatais pode ocorrer não só pelos formatos institucionalizados, mas também por arranjos participativos criados pela própria sociedade. A metodologia inclusiva utilizada pela FTP para estimular a população a realizar o controle democrático dos investimentos públicos transfere um valor para a sociedade relacionado, especialmente, com o compromisso cívico de vigilância e responsabilidade pública sobre os gastos do Estado, forçando a transparência e a resposta dos gestores às demandas e aos valores da população.

De acordo com o pensamento gramsciano, é impossível separar conflito e consenso. Dizendo de outra forma, é a partir do confronto que se constroem os consensos e é nessa dialética que a FTP estimula a prática do controle social democrático nos municípios piauienses e o caminho escolhido e trilhado, a partir da estratégia da Marcha Contra a Corrupção e Pela Vida, aponta saídas para a atuação da sociedade civil que geram efeitos na prevenção e no combate à corrupção. Não sem percalços, em uma realidade social permeada por tensões, próprias do sistema capitalista operante, que formam barreiras frente aos interesses de classes antagônicas, mas que constrói consensos para criar dinâmicas de participação ativa da sociedade na gestão estatal.

R. Inter. Interdisc. INTERthesis, Florianópolis, v.13, n.3, p.23-42 Set.-Dez. 2016 


\title{
ANTI-CORRUPTION FIGHT AS ACTIVE CITIZENSHIP EXERCISE
}

\begin{abstract}
:
This article discusses about the engendered initiatives in the civil society dimension to oversee public accounts, by exercising active citizenship in perception of anticorruption fights. It is the result of a PhD research in Public Policy, bounded by the state of Piaui, that brings as theoretical contribution the expansion of the concept of social control to democratic control in the context of Brazilian society. Empirical research was carried out by direct observation, through participant observation, along with the experience lived by the Força Tarefa Popular (FTP). FTP is a society pivotal movement of that, since 2002, has conducted a sensitization and mobilization work of people and entities for citizen practice to directly supervise public investment to prevent and combat corruption.
\end{abstract}

Keywords: Active Citizenship. Democratic Control. Fight gainst Corruption.

\section{LUCHA CONTRA LA CORRUPCIÓN COMO EJERCICIO DE CIUDADANÍA ACTIVA}

Resumen:

Este artículo discute acerca de las iniciativas que han surgido en la dimensión de la sociedad civil para la fiscalización de las cuentas públicas, mediante el ejercicio de la ciudadanía activa en vista de la lucha contra la corrupción. Es el resultado de una investigación de doctorado en Políticas Públicas, que se define en el estado de Piauí (Brasil), trayendo como discusión teórica la ampliación del concepto de control social para control democrático en el contexto de la sociedad brasileña. La investigación empírica fue llevada a cabo por medio de la observación directa a la luz de la observación participante, con la experiencia vivida por la Fuerza Tarefa Popular (FTP), un movimiento de articulación de la sociedad que, desde 2002, realiza un trabajo de sensibilización y movilización de personas y entidades para la práctica ciudadana para controlar de forma directa las inversiones públicas, para prevenir y combatir la corrupción.

Palabras clave: Ciudadanía Activa. Control Democrático. Lucha contra la Corrupción. 


\section{REFERÊNCIAS}

AMARRIBO - BRASIL. < http://www.amarribo.org.br />. Acesso em: 10 mar. 2014.

ARTICULAÇÃO BRASILEIRA CONTRA A CORRUPÇÃO E IMPUNIDADE (ABRACCl). < http.www.abracci.org.br >. Acesso em: 10 mar. 2014.

ARENDT, Hannah. As esferas pública e privada. In. A condição humana. Rio de Janeiro: Forense Universitária, 1997.

ARRETCHE, Marta. Emergência e desenvolvimento do Welfare State. Boletim Informativo e Bibliográfico de Ciências Sociais (BIB), n. 39, 1995. p. 3-40.

AVRITZER, Leonardo (Org.). Corrupção: ensaios e críticas. Belo Horizonte:Ed. UFMG, 2008.

AVRITZER, Leonardo; FIGUEIRAS Fernando. Corrupção e controles democráticos no Brasil. Brasília, DF: CEPAL. Brasil/IPEA, 2011.

BAROWIAK, Graig. Accountability \&Democracy: the pitfalls and promise of popular control. Oxford: Oxford University Press. 2011.

BOFF, Leonardo. Alimentando a nossa mística. In: Mística: uma necessidade no trabalho popular e organizativo. Caderno de Formação, MST, n. 27, 1993.

BRASIL. Constituição Federal. São Paulo: Manole, 2003.

BRASIL. CONTROLADORIA GERAL DA UNIÃO (CGU). < http://www.cgu.gov.br >. Acesso em: 24/mar./2014.

BRASIL. TRIBUNAL DE CONTAS DA UNIÃO (TCU). < http://www.tcu.gov.br>. Acesso em: 24 mar. 2014.

BRASIL. MINISTÉRIO PÚBLICO FEDERAL (MPF). < http://www.mpf.gov.br>. Acesso em: 24 mar. 2014. 
CÂMARA FEDERAL. Projetos de lei e outras disposições. Disponível em: < http://www.camara.gov.br/proposicoesWeb/ >. Acesso em: 12 jun. 2014.

CHAUÍ, Marilena. Cultura e democracia. São Paulo: Editora Moderna, 1984.

CORREIA, Maria Valéria Costa. O Conselho Nacional de Saúde e os rumos da política de saúde brasileira: mecanismos de controle social frente as condicionalidades dos organismos financeiros internacionais. 342 f. [Tese Doutorado] Universidade Federal de Pernambuco, Recife, 2005.

COUTINHO, Carlos Nelson. Contra a Corrente: ensaios sobre democracia e socialismo. 2. ed. São Paulo: Cortez, 2008.

DURIGUETTO, Maria Lúcia. Sociedade civil e democracia: um debate necessário. São Paulo: Cortez, 2007.

FILGUEIRAS, Fernando. Corrupção, democracia e legitimidade. Belo Horizonte: Ed. UFMG, 2008.

FILGUEIRAS, Fernando. Transparência e controle da corrupção no Brasil. In: AVRITZER, Leonardo; FILGUEIRAS, Fernando (org). Corrupção e sistemas políticos no Brasil. Rio de Janeiro: Civilizações Brasileira, 2011.

FORÇA TAREFA POPULAR (FTP). < http://forcatarefapopular.blogspot.pt/ > Acesso em: 12 jun. 2014.

GRAMSCI, Antonio. Cadernos do cárcere: Maquiavel; notas sobre o Estado e a Política. $1^{\mathrm{a}}$ ed. Rio de Janeiro: Civilização Brasileira, 2000.

KLITGAARD, Robert. A corrupção sobre controle. Trad. Octavio Alves Velho. Rio de Janeiro: Jorge Zahar, 1994.

MARSHAL, T.H. Cidadania, Classe Social e Status. Trad. Meton Porto Gadelha Rio de Janeiro: Zahar, 1967.

MARX, Karl. A guerra civil na França: crítica ao Programa de Gotha. In: MARX, Karl; ENGELS, Friedrich. Ed. eletrônica: Ridendo Castigat Mores, 1999. Disponível 
em: < http://www.ebooksbrasil.org/adobeebook/guerracivil.pdf > . Acesso em: 14 out. 2013.

MATOS, Teresa Cristina C. Democracia direta como mecanismo de controle social e combate à corrupção: a experiência da Força Tarefa Popular. 2015.193 f. [Tese Doutorado] Universidade Federal do Piauí, Teresina, 2015.

MOVIMENTO DE COMBATE A CORRUPÇÃO ELEITORAL (MCCE). <http// www. mcce. org.br> Acesso em: 12 jun. 2014.

NETTO, J. P. Introdução ao estudo do método em Marx. $1^{\text {a }}$ ed. São Paulo: Expressão popular, 2011.

NOGUEIRA, Marco Aurélio. Um Estado para a sociedade civil: temas éticos e políticos da gestão democrática. $2^{\circ}$ ed. São Paulo: Cortez, 2004.

NOGUEIRA, Marco Aurélio. As ruas e a democracia. Ensaios sobre o Brasil contemporâneo. Brasília: Fundação Astrojildo Pereira (FAP); Rio de Janeiro: Contraponto, 2013.

PEREIRA, Luiz Carlos Bresser, SPINK, Peter. Reforma do Estado e Administração Pública Gerencial. Rio de Janeiro: Editora Fundação Getúlio Vargas, 1999.

PEREYRA. Sebastián. Política y transparencia: la corrupción como problema público. Buenos Aires: Siglo Veintiuno Editores, 2013.

PINTO, Celi Regina. A Banalidade da corrupção: uma forma de governar o Brasil. Belo Horizonte: Editora UFMG, 2011.

PRZEWORSKI, Adam. Democracy and the Limits of Self-Government. Cambridge: Cambridge University Press, 2010.

PROGRAMA DAS NASÇÕES UNIDAS PARA O DESENVOLVIMENTO (PNUD). Disponível em: < www.pnud.org.br/Noticia.aspx?id=3663 >. Acesso em 16 jun. 2014.

ROSE-ACKERMAN, Susan. Corrupção e Governo. Trad. A. Mata. Lisboa Portugal: Prefácio, 2002. 
SENADO FEDERAL. Portal Atividade Legislativa. Disponível em: <http://www.senado.gov.br/atividade/ >. Acesso em: 12 jun. 2014.

SIMIONATTO, I. Razões para continuar utilizando a categoria sociedade civil. In: LUIZ, D. C. (org). Sociedade civil e democracia: expressões contemporâneas. São Paulo: Veras, 2010.

SPECK, Bruno Wilhelm (org.). Caminhos da transparência. Campinas: Ed. Unicamp, 2002.

STUKART, Herbert Lowe. Ética e corrupção: os benefícios da conduta ética na vida pessoal e empresarial. São Paulo: Nobel, 2003.

THUROW, Lester C. O Futuro do Capitalismo: como as forças econômicas mudam o mundo de amanhã. Rio de Janeiro: Rocco,1997.

TRANSPAREANCIA INTERNACIONAL (TI). < http://www.transparency.org >. Acesso em: 23 mar. 2014.

WEBER, Max. A Política como Vocação. In: Ensaios de Sociologia. Rio de Janeiro: Ed. Guanabara, 1982.

Artigo:

Recebido em 20 de Janeiro de 2016

Aceito em 25 de Julho de 2016

R. Inter. Interdisc. INTERthesis, Florianópolis, v.13, n.3, p.23-42 Set.-Dez. 2016 